\title{
ЗНАЧЕНИЕ ОРГАНИЗАЦИИ ОБЪЕДИНЕННЫХ НАЦИЙ ПО РЕШЕНИЮ ПРОБЛЕМ ГОСПОДСТВА ПРАВА В КОНФЛИКТНЫХ ГОСУДАРСТВАХ
}

Аннотация. Предметом исследования выступает значение Организации Объединенных Наций по решению проблем господства права в конфликтных государствах.Целью исследования является анализ основных, извлеченных из деятельности Организации Объединенньх Наций по утверждению принципа господства права в государствах, направлений деятельности. Рассматривается многолетний опыт организации в сфере урегулирования конфликтов. В основу исследования положен общенаучный диалектический метод познания, предполагающий изучение правовых явлений и понятий в их развитии и взаимообусловленности. Применялись и логико-юридический (догматический), сравнительный методы. Основными выводами проведенного исследования, во-первых, является утверждение необходимости уделения внимания ООН восстановлению и уважению господства права и оказание поддержки господству права в конфликтных государствах. Во-вторых, автор подчеркивает что ООН в своих резолюииях должна настаивать на необходимости справедливого судопроизводства для решения проблем связанных с конфликтными ситуациями. В-третьих, автор обращает внимание на необходимость признания и уважения прав потерпевших и обвиняемых в соответствии смеждународными стандартами при уделении особого внимания группам населения, пострадавшим детям, женщинам, заключенным и другим лицам в результате конфликта.

Ключевые слова: Проблемы правосудия, принцип верховенства права, Совет Безопаснотси ООН, миротворческие операции, стандарты ООН, поддержка господства права, поддержка правосудия, правосудия переходного периода, Международный уголовный суд, реформа правосудия. Abstract: The goal of this research is to analyze the main vectors of the efforts of United Nations in strengthening the rule of law within countries. The author reviews the decades-long record of the organization in the area of conflict resolution. The main conclusions of the conducted research include: firstly, the pressing need for UN to give more attention to restoration and respect of the rule of law, and providing support for the rule of law within conflict states; secondly, the author underlines that UN should stress in its resolutions the necessity of a just court procedure in resolving problems pertaining to conflict situations. Thirdly, the author notices the need to recognize and respect the rights of the victims and defendants in accordance with international standards, taking into account the specific social groups, women, children, prisoners and other individuals who have suffered as a result of a conflict.

Keywords: Supporting justice, supporting the rule of law, UN standards, peacekeeping missions, UN Security Council, rule of law, problems in justice system, justice of the transitional period, International Criminal Court, justice reform.

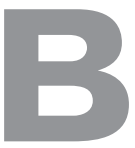

последние годы Организация Объединенных Наций стала уделять повышенное внимание проблемам господства права в конфликтных государствах, благодаря чему были извле178 чены важные уроки для нашего дальнейшего исследования указанной проблемы.

Мир, справедливость и демократия - это не взаимоисключающие цели, а наоборот, императивы, дополняющие друг друга. 
Для утверждения всех этих идеалов во взрывоопасных государствах, на наш взгляд необходимо стратегическое планирование мероприятий, их тщательное увязывание между собой и выстраивание их в некоей логической последовательности, касающихся проблем господства права в каждом взятом в отдельности государства.

Генеральная ассамблея ООН 8 сентября 2000 г. в своей декларации на новое тысячелетия посчитала, что существенное большое значение для международных отношений в XXI веке будет иметь ряд фундаментальных ценностей одним из поставленных задач - укрепление уважение к принципу верховенство права.

«Верховенство права» - это понятие, составляющее саму суть миссии Организации Объединенных Наций. Соблюдение законности имеет фундаментальное значение для обеспечения устойчивого мира после урегулирования конфликта, для эффективной защиты прав человека и для устойчивого экономического прогресса и развития. Принцип, согласно которому все - от отдельного взятого человека вплоть до самого государства - обязаны соблюдать законы, которые были публично приняты, в равной степени исполняются и независимо реализуются судебными органами, лежит в основе концептуального подхода, в значительной степени направляющего работу Организации Объединенных Наций [1].

Принцип верховенства права, закрепленный в Уставе Организации Объединенных Наций, включает в себя элементы, касающиеся отношений между государствами. Основным органам Организации Объединенных Наций, включая Генеральную Ассамблею и Совет Безопасности, отводятся в этой связи ключевые функции, которые вытекают из Устава Организации и подразумевают принятие мер в соответствии с его положениями.

Думается, что для Организации Объединенных Наций верховенство права означает такой принцип управления, в соответствии с которым все учреждения и структуры, государственные и частные, в том числе само государство, функционируют под действием законов, которые были публично приняты, в равной степени исполняются и независимо реализуются судебными органами и которые совместимы с международными нормами и стандартами в области прав человека. Для этого также необходимы меры, обеспечивающие соблюдение принципов примата права, равенства перед законом, ответственности перед законом, беспристрастного применения законов, разделения властей, участия в принятии решений, правовой определенности, недопущения произвола и процессуальной и правовой транспарентности.

Полагаем, что Организация Объединенных Наций на этот счет обязана уделять объективное, справедливое и повышенное внимание международной уголовной юстиции, в частности проблемам господства права. На наш взгляд, успех этой работы должен зависит от ряда важных факторов, включая необходимость обеспечить основу в виде международных норм. И в тоже время мобилизовать необходимые ресурсы в систему отправления правосудия. Думается, что на этот счет следует воздержаться от использования неких универсальных форм и искусственного насаждения инородных моделей, а 
вместо этого оказывать свою помощь на основе национального участия.

Считаю, что Организация Объединенных Наций обязана поддерживать национальные идеи, продвигающие реформы в системе уголовной юстиции по вопросам правосудия и оказывать помощь в заполнении правового вакуума, который образовался в столь многих постконфликтных субъектах международного права.

Уверен в том, что мир, справедливость и демократия - это не взаимоисключающие цели, а, наоборот, императивы, дополняющие друг друга. И для утверждения всех этих трех идеалов во конфликтных государства должно быть осуществлено стратегическое планирование тех мероприятий, которые бы увязывали и выстраивали между собой господство права в логической последовательности. Считаю, что в Организации Объединенных Наций подход к системе господства права должен быть всеобъемлющим с точки зрения уделения особого внимания всем взаимосвязанным институтам правосудия, а Международному суду ООН в частности. И считаем, что задача Организации Объединенных Наций должна состоять в том, чтобы помочь государствам в укреплении основ господства права и национальной системы юстиции.

Цель настоящей статьи, заострить внимание на основных вопросах, извлеченных из деятельности Организации Объединенных Наций по утверждению принципа господства права в субъектах международного права за последний двадцатилетний опыт. Такой опыт показывает, что упрочение мира непосредственно в постконфликтный период, ровно, как и поддержание мира в долгосрочной перспективе будет невозможным, если население государств не будет уверено в том, что оно может добиться мира, урегулирования споров и справедливого отправления правосудия и господства права своей территории. В то же время повышенная уязвимость перемещенных, беженцев и других групп, которые имеют место во всех конфликтных ситуациях, диктует необходимость безотлагательного решения таких важных задач, как восстановления господства права.

Хотелось бы обратить внимание на оказание помощи населению пережившим войну в восстановлении господства права и ликвидации последствий крупномасштабных нарушений законности, причем в условиях, когда инфраструктура разрушена, ресурсы истощены, общая ситуация остается неспокойной, а населения государства психологически травмировано и разделено, это весьма сложная задача.

Нормативной основой для рассмотрения обозначенной выше проблемы является сам Устав Организации Объединенных Наций наряду с тремя важными проблемами современной международной правовой системы: международными стандартами в области прав человека; международным гуманитарным правом и международным уголовным правом. Считаю, что сюда входит полный набор стандартов Организации Объединенных Наций в области прав человека, и они представляют собой общеприемлемые стандарты, принятые Организацией Объединенных Наций, и поэтому служат нормативной основой для всей деятельности Организации Объединенных Наций в поддержку правосудия и господства права.

Если же обратиться к нормам и стандартам Организации Объединенных Наций то они разрабатываются и принимаются 
всеми государствами мира и включаются в правовые системы государств-участников, независимо от того, основаны ли они на той или иной правовой системе. И благодаря этому эти нормы и стандарты должны обеспечивать легитимность, устанавливать нормативные границы участия Организации Объединенных Наций. И все это должно способствовать тому, что суды, образованные под эгидой Организации Объединенных Наций не могут применять смертную казнь [2] . На наш взгляд никоим образом в мирных соглашения, одобренных Организацией Объединенных Наций, не может быть предусмотрена амнистия за международные преступления и в тех случаях, когда учреждения, действующие под управлением Организации Объединенных Наций на осуществления судебных функций, обязаны соблюдать международные стандарты в области прав человека.

Думается, что при вынесении рекомендаций, на сегодняшний день, Организацией Объединенных Наций необходимо тщательно рассматривать конкретные потребности каждого принимающего государства в области обеспечения господства права. В соответствии с этим полагаем, должны быть оценены последствия мирных соглашений, касающихся господства права, и условия и характер правовой системы каждого в отдельности взятого государства, её традиции и институты.

Необходимо отметить, что Организация Объединенных Наций не всегда предоставляла помощь по обеспечению господства права, которая бы способствовала особенностям государства. В то же время Организация Объединенных Наций на сегодняшний день уделяет внимание стратегиям оценки и консультаций под национальным руководством, осуществляемым при активном и существенном участии национальных заинтересованных сторон, в том числе должностных лиц сектора правосудия. И на этот счет следует отметить, что национальные органы обязаны брать на себя руководство в проведении обследования господства права путем мобилизации национальных специалистов в области права.

Полагаем, что в рамках указанных процессов Организация Объединенных Наций обязана оказывать помощь в проведении совещаний, консультаций по правовым вопросам, оставляя при этом руководство и принятия решений за национальными заинтересованными должностными лицами конкретно взятого государства.

Думается, что в большинстве случаев успех деятельности в области господства права во многом обусловлен большим числом и высоким качеством консультаций, проводимых с общественностью и жертвами преступлений. Такие консультации должны лучше понять динамику, характерные черты дискриминации и мотивы совершаемых преступлений. Хочется отметить, что нельзя надеяться на успех или стабильность реформ в интересах господства права, которые насаждаются извне (суд присяжных в России по американскому сценарию). Думается, что роль Организации Объединенных Наций и международного сообщества в целом должна заключаться не в подмене, а в проявлении солидарности по реализации господства права. На наш взгляд принципиально важно обеспечить, чтобы эти условия были основаны на существенном участии общественности с привлечением национальных специалистов в области 
права, правительства, гражданского общества. Важным является то, что программы Организации Объединенных Наций по вопросам господства права должны обеспечить выявление, поддержку и наделение правами национальных участников реформ. Так, на примере Украины, в ходе миротворческих операций, локализации внутри государственного конфликта нужно лучше оказывать помощь участникам в целях развития их собственного видения реформы, их собственных подходов к господству права переходного периода. И наиболее важная роль, заключается в содействии процессам, на основе которых различные заинтересованные участники излагают в общих чертах элементы плана их государства по устранению и проявлений несправедливости в соответствии с международными стандартами. И на этот счет международное сообщество обязана поддержать институты государства в реформе господства права, оставаясь в то же время верными международным нормами и стандартам.

Думается, что поддержку реформ господства права и системы правосудия необходимо культивировать среди бывших комбатантов и (не уголовных) элементов бывших режимов, причем все они должны быть заверены в том, что они будут защищены от незаконного и несправедливого возмездия. Надо заметить, что в условиях рассмотрения процессов реформирования господства права одними из особенно важных участников выступают жертвы государства [3]. На этот счет, на наш взгляд, Организация Объединенных Наций должна оценивать и уважать интересы жертв при разработке и осуществлении на практике мер в области правосудия переходного периода.
Считаем, что в эффективных стратегиях обеспечения господства права акцент должен непременно делаться на правовые институциональные потребности, должное внимание следует уделять политическим элементам. Большой интерес общественности вызывает деятельность по планированию реформ системы обеспечения господства права и согласованию процессов отправления правосудия. Полагаем, что на этот счет, эти вопросы являются обязательным предметом серьезных консультаций на уровне общественности и носят политический характер. Думается, что оценку деятельности учреждений, которым оказывается международная помощь, нельзя проводить с точки зрения лишь повышения ее эффективности без учета их приверженности делу обеспечения прав человека или ответственности за организуемые ими публичные дискуссии. Нам кажется, что в ряде случаев власти больше обеспокоены консолидацией власти, чем укреплением господства права, при этом последнее зачастую воспринимается как угроза для первой. Поэтому высокопоставленные представители Организации Объединенных Наций в этой области обязаны уделять пристальное внимание поддержке политических аспектов реформ в области систем правосудия и господства права. Нам кажется, что их добрые услуги могут иметь решающее значение для обеспечения реформаторам политического пространства, ограждения правоохранительной системы от политического насилия и мобилизации ресурсов в целях укрепления господства права.

Анализируя деятельность международного сообщества, можно сказать, что оно довольно часто недооценивает ту 
степень политической воли, которая необходима для поддержания эффективной реформы системы обеспечения господства права в постконфликтных государствах, и в тоже время не прилагает должных усилий для проведения публичных консультаций по вопросам перестройки системы правосудия. Поэтому в стратегиях, касающихся системы отправления правосудия игнорируется необходимость содействовать достижению консенсуса между основными заинтересованными сторонами в отношении создания новых институтов [4].

Следует отметить довольно важный факт, что реформы системы обеспечения господства права и деятельность по обеспечению отправления правосудия переходного периода нередко проводятся одновременно с выборами представителей государственной власти. Такие процессы, на наш взгляд, имеют довольно важное значение для обеспечения их успеха и легитимности. Полагаем, это означает, что миротворческие операции Организации Объединенных Наций планируются как краткосрочные мероприятия и анализирую прошлую практику формирование системы обеспечения господства права и развития демократии, можно сказать - сам этот процесс довольно длительный. Поэтому, занимаясь стратегическим планированием, на наш взгляд, следует учитывать необходимость установления этапов и организации международной помощи, которую выполняет Организация Объединенных Наций после завершения миротворческой миссии.

Необходимо подтвердить тот факт, что на сегодняшний день на территории Украины отсутствует согласованность между структурами государственной власти к обеспечению господства права и такие действия не принесут удовлетворительных результатов по случаю переживших сторонами конфликта ужасов войны. Мы считаем, что эффективные стратегии обеспечения господства права должны быть всеобъемлющими и на этот счет должны быть задействованы все институты системы господства права, как правительственные, так и неправительственные. Считаем, что такие стратегические направления должны быть направлены на принятия конституции, нормативной базы, которые их осуществляют, контролируют, и граждане государств должны иметь к ним доступ. Эти примеры проанализированы и автором извлечены из многолетнего опыта работы Организации Объединенных Наций в рассматриваемой области. Можно сказать, что иногда международные усилия направляются на восстановление полицейских служб, практически оставляя без внимания другие направления системы обеспечения правосудия. Например, законотворческая деятельность, профилактика преступности, совершенствование судебной системы, юридическое образование, реформирование уголовно-исполнительной, прокурорской системы, защита и поддержка жертв и гражданского общества - на наш взгляд все эти направления имеют существенное значение для обеспечения господства права и все они взаимозависимы. Полагаем, что упущения одного из указанных направлений неизбежно ведет к ослаблении других. В других же случаях международное сообщество в поспешном порядке предписывало конкретную формулу правосудия переходного периода, при этом делая акцент только на уголовном преследовании, 
вместо того, чтобы первым порядком дать возможность жертвам и национальным субъектам подумать и принять решения с учетом местным обычаев и особенностей субъекта международного права.

Считаем, что вызовы постконфликтных ситуаций требуют разработки подхода, разумно сочетающего разнообразие целей и направлений, включая обеспечения ответственности, поиску истины, обеспечения сохранения мира, формирование демократии и господства права.

Полагаем, что на этот счет необходимо обратить внимание на тот случай, что в постконфликтных ситуациях законодательная база имеет многочисленные признаки политических перекосов и пренебрежения, по другому, можно сказать, содержит дискриминационные элементы и довольно редко отражает требования международных стандартов в области прав человека и международного уголовного права. Например, принимаемые чрезвычайные законы в некоторых государствах, довольно часто представляют собой обычные локальные нормы. Законы, которые имеются на бумаге, о них может не знать широкая общественность, а официальные государственные лица не имеют ни возможности, ни инструментов для их функционирования. Например, национальные судебные, полицейские и пенитенциарные (тюремные) системы государств не имеют финансовых, материальных и людских ресурсов, необходимых для их надлежащего функционирования. Следует констатировать тот факт, что на сегодняшний день на Украине для таких возникающих ситуаций неизменно характерны наличие большого количества оружия, преследований по признаку пола, сексуального насилия, эксплуатация детей, организованная преступность, торговля людьми, контрабанда, коррупция и другие виды преступной деятельности. Полагаем, что в таких случаях организованные преступные группировки намного лучше обеспечены ресурсами, чем местные органы власти, и на много лучше вооружены, чем местные правоохранительные органы.

Автор приходит к выводу, что миротворческие операции которые проводит Организация Объединенных Наций обязана помочь государствам заполнить этот вакуум в области господства права.

Следует также отметить, что Организация Объединенных Наций сталкивается с определенными трудностями в проведении миротворческих операций, когда вообще отсутствуют в государствах механизмы уголовного правосудия. И в таких случаях, как видно из практики, миротворцам противостоят преступные элементы, совершающие тяжкие и особо тяжкие преступления, создавая непосредственную угрозу для населения государства и для самой миротворческой операции. Следует обратить внимание, что военные подразделения, как правило, не имеют достаточной подготовки, навыков и ресурсы для борьбы с преступными элементами. В свою же очередь гражданские компоненты миротворческих операций, включая полицию, очень медленно развертываются. Полагаем, что такое беззаконие может серьезно подорвать усилия всей миротворческой операции. Организация Объединенных Наций, с учетом указанных реалий вместе с государствами-членами обязаны переосмыслить указанные стратегии в целях заполнения вакуума в области господства права. 
Обращаем внимание на то что международное сообщество в лице Организации Объединенных Наций неоднократно предпринимало и предпринимает непосредственные шаги по защите прав человека и его безопасности в условиях, когда в результате разрушается и перестает действовать внутренняя система обеспечения господства права.

Анализируя практику Организации Объединенных Наций видно, что её учреждения на протяжении многих десятилетий оказывает помощь странам укреплять свои национальные системы по решению проблем господства права в соответствии с международными стандартами. На этот счет полагаю, что законодательство государств должно соответствовать международным стандартам в области прав человека и отвечать текущим потребностям и национальным особенностям конкретной страны. Считаем, что институциональным стержнем систем, опирающихся на господство права, должна быть сильная и независимая судебная система, оснащенная и подготовленная для защиты прав человека при отправлении правосудия. Считаем, что не менее важными являются институты системы отправления правосудия - полицейские службы, следственные органы, пенитенциарные системы и гильдии адвокатов, ассоциации юристов, которые должны стоять на страже прав человека, гражданина[5].

Акцентируя внимание на создании формальной системы отправления правосудия, которая функционирует эффективно и в соответствии с международными стандартами, крайне важно остановиться на функционировании дополнительных механизмов, которые успешно функцио- нируют в соответствии с международными стандартами. Например, независимые национальные комиссии по правам человека играют жизненно важную роль в обеспечении ответственности, правовой помощи, урегулировании споров и защиты прав человека в переходной период. Думается, что на этот счет при отправлении правосудия и урегулировании споров необходимо должным образом учитывать местные и неформальные традиции, с тем, чтобы они продолжали решать свою важную роль и осуществляли свою деятельность в соответствии, как с международными стандартами, так и с местными традициями. Полагаем, что отказ от них может сделать господство права недоступным для отдельных групп общества. Крайне важны в этих обстоятельствах меры по обеспечению учета гендерного фактора в работе господства права.

Организация Объединенных Наций в значительной мере поддерживает, оказывает помощь и имеет наилучший шанс с точки зрения содействия устойчивому совершенствованию господства права.

На этот счет, Организация Объединенных Наций учредила целый ряд специальных уголовных трибуналов или содействовала их учреждению. При этом она стремилась к достижению ряда целей, в частности предать суду ответственность за серьезные нарушения прав человека и гуманитарного права, положить конец преступлениям и не допустить повторное проявление. В то же время восстановить справедливость для жертв и их достоинство, восстановить господство права и содействовать восстановлению мира. В целях достижения этого был создан ряд институционных моделей. К ним можно отнести специализированные междуна- 
родные уголовные трибуналы, учрежденные Советом Безопасности в качестве вспомогательных органов Организации Объединенных Наций по бывшей Югославии (Международный уголовный трибунал по бывшей Югославии) и по Руанде (Международный уголовный трибунал по Руанде); смешанный трибунал по Сьерра-Леоне, учрежденный как суд на основе договора; смешанный трибунал по Камбодже, предложенный в соответствии с национальным законом, специально принятым в соответствии с договором; смешанный трибунал (устроенный как «суд в суду») в форме специальной камеры в Государственном суде Боснии и Герцеговины. Ныне действующая Коллегия, обладающая исключительной юрисдикцией в отношении тяжких уголовных преступлений в Тиморе-Лешти, созданная Временной администрацией Организации Объединенных Наций в Восточном Тиморе. Необходимо отметить, что международные уголовные трибуналы, Международный уголовный трибунал по бывшей Югославии и Международный уголовный трибунал по Руанде, сыграли важную роль в достижении правосудия в бывшей Югославии и Руанде. В результате их работы усилия правового характера по привлечению преступников к ответственности будет теперь легче осуществлять благодаря прояснению вопросов, как по военным преступлениям, так и преступлениям против человечности, геноцида и других тяжких преступлений.

Наиболее важным событием последних десятилетий в длительной борьбе международного сообщества по достижению прогресса в деле обеспечения правосудия и господства права стало учреждение постоянно действующего Международного уголовного суда[6].

Вновь образованный постоянно действующий Международный уголовный суд 1998 г. дает новую надежду на то, что борьба безнаказанностью выйдет на качественно новый уровень.

Можно с уверенностью отметить, что господство права, на наш взгляд представляет собой обширные основные области, которые находятся в центре внимания Организации Объединенных Наций. Например, в 2002 г. Исполнительный комитет по вопросам мира и безопасности ООН утвердил Заключительный доклад общесистемной Целевой группы в целях рассмотрения подходов Организации Объединенных Наций к господству права в рамках миротворческих операций. На этот счет, Целевая группа выработала рекомендации с целью более эффективного решения вопросов господства права в рамках миротворческих операции Организации Объединенных Наций.

Анализируя формирования господства права в государствах, переживающих конфликт в целях укрепления поддержки Организации Объединенных Наций Комиссия по вопросам мира и безопасности ООН обязана проанализировать и разработать предложения по укреплению механизма системы Организации Объединенных Наций для оказания поддержки господства права в государствах, переживающих конфликт. Считаю, что Комиссии по вопросам мира и безопасности ООН должна разработать подходы для обеспечения того, чтобы все стратегии, программы были направленные на поддержку конституционных, судебных и законодательных реформ и способствовали господству права. 
В то же время для расследования ранее совершенных преступлений в переживших войнах государств создавались международные или смешанные трибуналы. Они помогали добиться справедливости и дать надежду потерпевшим, бороться с безнаказанностью преступников и обогатить практику уголовного судопроизводства. Необходимо отметить, что эти трибуналы, однако, требовали больших финансовых затрат и мало чем помогли в создании жизнеспособной национальной системы юстиции.

Как уже упоминалось, наиболее важным событием последнего времени в длительной борьбе Организации Объединенных Наций по достижению прогресса в деле обеспечения правосудия и господства права стало учреждения 17 июля 1998 г. Международного уголовного суда. Статут Международного уголовного суда вступил в силу 1 июля 2002 г.

Международный уголовный суд дает новую надежду на то, что борьба с безнаказанностью выйдет на качественно новый уровень, и поэтому ратификацию его статуса все новыми государствами необходимо всячески поощрять.

Международный уголовный суд (МУС), юрисдикция которого тщательно сформулирована в Римском статуте, является первым постоянным международным судом, созданным на договорной основе для содействия прекращению безнаказанности за многочисленные тяжкие преступления, совершенные в XXI веке.

МУС является самостоятельным по отношению к Организации Объединенных Наций международным органом. МУС оказывает важное содействие на потенциальных нарушителей, напоминая им о том, что безнаказанность не гаранти- рована, и выполняет роль катализатора в принятии национальных законов об ответственности за наиболее тяжкие международные преступления.

По состоянию на февраль 2015 г., Статут МУС ратифицировало 123 государства (Палестина ратифицировала Римский Статут 2 января 2015 г.), всего Римский Статут подписало 139 государств из 193 государств-членов ООН, но ратифицировали соглашение не все.

Российская Федерация подписала Римский статут 13 сентября 2000 года, однако ещё не ратифицировала его и, таким образом, государством-участником Международного уголовного суда не является. При этом Россия сотрудничает с МУС и участвует в его работе в качестве наблюдателя. В то же время, мы убежден в том, что Российская Федерация - член Совета Безопасности ООН, которая еще не ратифицировала Статут, должна как можно скорее принять меры для ратификации Римского Статута.

В то же время ряд стран принципиально возражает против самой идеи МУС как ограничивающей суверенитет государств и дающей неопределённо широкие компетенции суду; среди них США, Китай, Индия, Израиль и Иран.

Самым ярым противником деятельности МУС является США. Правительство США хотя и подписало Римский статут в 2000 году, но уже в 2002 году отозвало свою подпись. Изначально, экс президент США Билл Клинтон, подписывая документ, объяснил, что США не собираются ратифицировать Римский статут, пока в полной мере воочию не ознакомятся с работой Международного уголовного суда [7]. В дальнейшем уже администрация экс президента США Бушамладшего под предлогом защиты своих 
военнослужащих полностью отказалась от участия в Римском статуте, назвав его нарушающим национальные интересы и суверенитет США. Кроме того в 2002 году был принят специальный Закон о защите американского персонала за рубежом, который разрешил применение военной силы для освобождения любого американского гражданина либо граждан из числа союзников США, задержанных на территории какого-нибудь государства по ордеру МУС. Также США заключили двусторонние соглашения с рядом стран, в которых обязали их не выдавать подозреваемых американских граждан Международному уголовному суду, а в случае нарушения этих договорённостей США прекратят оказывать им военную помощь и любую иную поддержку.

Полагаем, что Организация Объединенных Наций должна обеспечить это новое учреждение ресурсами, потенциалом, информацией и поддержкой, тем, в чем МУС для расследования нарушений, преследования и привлечения к судебной ответственности тех, кто несет ответственность за преступления против человечества, военные преступления, геноцида и агрессии, в случаях, когда судебная система государств не могут или не хотят привлечь виновных к ответственности. На этот счет, в соответствии с Статутом МУС, Совет Безопасности ООН призван сыграть особую роль в этой связи, выступая в качестве органа, наделенного правом передавать вопросы на рассмотрения МУС, даже в тех случаях, когда затрагиваемые страны не являются государствамиучастниками Статута МУС.

Другим важным механизмом решения вопроса о злоупотреблениях в области прав человека в прошлом является комиссия по установлению истины. Данная комиссия ООН является официальным, временным несудебным органам по установлению фактов, которые расследует характер злоупотребления в области прав человека или гуманитарного права, совершавшихся на протяжении нескольких десятков лет (с 1993-2013 г.). Эта комиссия применяет свой подход с учетом положения жертвы и завершает свою работу подготовкой заключительного доклада, включающего установление фактов и рекомендации. На протяжении 20 лет было Организацией объединенных Наций было создано 30 комиссий по установлению истины, в том числе в Аргентине, Чили, Южной Африке, Перу, Гане, Марокко, Сальвадоре, Гватемале, Тиморе - Лешти и Сьерра-Леоне. Комиссия в Сальвадоре, Гватемале, Тиморе - Лешти и СьерраЛеоне. Следует заметить, что комиссии в Сальвадоре, Гватемале, Тиморе - Лешти и Сьерра-Леоне пользовались существенной помощью и поддержкой со стороны Организации Объединенных Наций, а миссии Организации Объединенных Наций в Либерии и Демократической Республике Конго оказывают сегодня поддержку консультативным процессам в отношении комиссий по установлению истины в этих странах. Думается, что эти комиссии способны принести большую пользу, помогая народам на этапе после конфликта устанавливать факты в связи с прошлыми нарушениями прав человека, тем самым укрепляя режим ответственности, сохраняя доказательства, выявлять нарушителей и вносить рекомендации в отношении организационных реформ правосудия переходного периода и господства права. Такие комиссии, исходя из своей юрисдикции, могут создавать общественную платформу для того, чтобы 
жертвы могли прямо делиться с народом своими личными историями, и содействовать общественному обсуждению вопроса о возможных путях примирения и обеспечить в решении вопросов правосудия переходного периода и господства права в конфликтах.

Считаем, что к числу факторов, которые могут, в какой-то мере, ограничить работу комиссий, могут относиться: политическая нестабильность, слабость гражданского общества, коррумпированность системы правосудия, боязнь жертв и свидетелей давать показания, отсутствие общественной поддержки и недостаточное финансирование.

Думается, что для успешной работы комиссии должны пользоваться реальной независимостью и использовать надлежащее доверия критерии в самом процессе отбора членов. Полагаем, эффективные государственные стратегии в области информации и коммуникации имеют важное значение для удовлетворения ожиданий общественности и жертв и уровня повышения доверия и транспарентности. Считаем, что на этот счет необходимо обеспечивать учет ими гендерного фактора и интересов жертв, а также жертв дискриминации. В то же время, многие комиссии потребуют в своей работе международной поддержки, а также уважения их оперативной независимости со стороны международных партнеров.

Таким образом, господство права представляют собой довольно основные области, которые находятся в центре внимания Организации Объединенных Наций в течение нескольких десятилетий..

Кроме Организации Объединенных Наций в эту работу вовлечено большое число субъектов международного права.
И мы считаем, что в этих обстоятельствах большое значение приобретает эффективная координация усилий.

В 2002г. Исполнительный комитет по вопросам мира и безопасности ООН утвердил Заключительный доклад общесистемной специальной Целевой группы в целях рассмотрения подходов Организации к правосудию и господства права в рамках миротворческой операции по поддержанию мира. Целевая группа выявила с точки зрения разнообразия и глубины значительный объем ресурсов и специальных знаний в вопросе господства права в системе Организации Объединенных наций, а также некоторые упущения. Целевая комиссия выработала рекомендации об оптимальных способах использования этих ресурсов и ресурсов, имеющихся вне подразделений $\mathrm{OOH}$, с целью более эффективного решения вопросов господства права в рамках миротворческих операций.

Думается, что доклад Целевой группы ООН представляет собой полезный каталог ресурсов, имеющихся в системе $\mathrm{OOH}$, и уже доказывает свою ценность для координации деятельности ООН по рассматриваемой проблеме. Таким образом, в качестве одной их последних мер в центральных учреждениях $\mathrm{OOH}$ была создана сеть координаторов по вопросам законности в составе квалифицированных специалистов из одиннадцати департаментов и учреждений ООН в целях содействия координации вопросов господства права и усилия ООН поддержки аспектов господства права в рамках миротворческих операций.

Полагаем, что для решения проблем господства права исключительно важное значение имеет то, чтобы миссии 
по поддержанию мира и сама система Организации Объединенных Наций взяли на себя обязательство действовать совместно друг с другом в рамках коллективных усилий, возглавляемых ключевыми субъектами гражданского общества и заинтересованными правительствами.

Считаем, во-первых, чтобы в резолюциях и мандатах Совета Безопасности $\mathrm{OOH} \mathrm{первоочередное} \mathrm{внимание} \mathrm{уделя-}$ лось восстановлению и уважению господства права и оказание поддержки господству права, особенно в тех случаях, когда для осуществления судебной и прокурорской работы требуется поддержка Организации Объединенных Наций. Во-вторых, чтобы в резолюциях Совета Безопасности ООН содержалось требование о том, чтобы все судебные процессы, суды вызывали доверие, были справедливыми, отвечали признанным международным стандартам в отношении независимой и беспристрастной судебной системы и эффективности, беспристрастности и непредвзятости прокуроров, а также целостности судопроизводства. В-третьих, чтобы Совет Безопасности ООН принимал резолюции, в которых содержалось признание и уважение прав потерпевших и обвиняемых в соответствии с международными стандартами при уделении особого внимания группам населения, пострадавшим детям, женщинам, заключенным и другим лицам в результате конфликта на решения господства права.

\section{Библиография:}

1. Байльдинов Е. Т. Возможности Организации Объединенных Наций обеспечения реализации норм международного права//Международное право и международные организации / International Law and International Organizations, №2-2011.

2. Костенко Н.И. Развитие концепции международного уголовного права в отечественной литературе// Государство и право. 2001. № 12. С. 88.

3. Костенко Н.И. Судопроизводство Международного уголовного суда - основа международного уголовного процесса // Государство и право. 2001. № 2. С. 64-70.

4. Кибальник А.Г. Современное международное уголовное право: понятие, задачи и принципы. СПб.: Изд. - во «Юридический центр Пресс», 2003. С. 17.

5. Каламкарян Р.А., Мигачев Ю.И. Всеобщая Декларация прав человека: роль и значение в условиях миропорядка на основе господства права Rule of Law. // Право и политика. 2008. № 12. C. 104-107.

6. Каламкарян Р.А. Международный суд ООН как административно-правовой орган мирового сообщества по мирному разрешению международных споров // Международное право и международные организации / International Law and International Organizations. 2011. № 2. С. 67.

7. Костенко Н.И. Международное сотрудничество Международного уголовного суда и судебная помощь//Право и политика. 2000. № 10. С. 105-112.

\section{References (transliterated):}

1. Bail'dinov E. T. Vozmozhnosti Organizatsii Ob"edinennykh Natsii obespecheniya realizatsii norm mezhdunarodnogo prava//Mezhdunarodnoe pravo i mezhdunarodnye organizatsii / International Law and International Organizations, №2-2011. 
2. Kostenko N.I. Razvitie kontseptsii mezhdunarodnogo ugolovnogo prava $\mathrm{v}$ otechestvennoi literature// Gosudarstvo i pravo. 2001. № 12. S. 88.

3. Kostenko N.I. Sudoproizvodstvo Mezhdunarodnogo ugolovnogo suda - osnova mezhdunarodnogo ugolovnogo protsessa // Gosudarstvo i pravo. 2001. № 2. S. 64-70.

4. Kibal'nik A.G. Sovremennoe mezhdunarodnoe ugolovnoe pravo: ponyatie, zadachi i printsipy. SPb.: Izd. - vo «Yuridicheskii tsentr Press», 2003. S. 17.

5. Kalamkaryan R.A., Migachev Yu.I. Vseobshchaya Deklaratsiya prav cheloveka: rol' i znachenie v usloviyakh miroporyadka na osnove gospodstva prava Rule of Law. // Pravo i politika. 2008. № 12. S. 104-107.

6. Kalamkaryan R.A. Mezhdunarodnyi sud OON kak administrativno-pravovoi organ mirovogo soobshchestva po mirnomu razresheniyu mezhdunarodnykh sporov // Mezhdunarodnoe pravo i mezhdunarodnye organizatsii / International Law and International Organizations. 2011. № 2. S. 67.

7. Kostenko N.I. Mezhdunarodnoe sotrudnichestvo Mezhdunarodnogo ugolovnogo suda i sudebnaya pomoshch'//Pravo i politika. 2000. № 10. S. 105-112. 